\title{
Evaluating effect of metallic ions on aggregation behavior of $\beta$-amyloid peptides by atomic force microscope and surface-enhanced Raman Scattering
}

\author{
Yang Xie ${ }^{1,2}$, Lin Yu², Yuna Fu², Heng Sun ${ }^{2}$ and Jianhua Wang ${ }^{2^{*}}$ (D)
}

\author{
*Correspondence: \\ wjh@cqu.edu.cn \\ 2 Key Laboratory \\ of Biorheological Science \\ and Technology, Ministry \\ of Education, and Institute \\ of Biochemistry \\ and Biophysics, College \\ of Bioengineering, \\ Chongqing University, \\ Chongqing 400044, China \\ Full list of author information \\ is available at the end of the \\ article
}

\begin{abstract}
Background: Excessive aggregation of $\beta$-amyloid peptides $(A \beta)$ is regarded as the hallmark of Alzheimer's disease. Exploring the underlying mechanism regulating $A \beta$ aggregation remains challenging and investigating aggregation events of $A \beta$ in the presence and absence of metallic ions at molecular level would be meaningful in elucidating the role of metal cations on interactions between $A \beta$ molecules. In this study, chemical self-assembled monolayer (SAM) method was employed to fabricate monolayer of $\beta$-amyloid peptides $A \beta 42$ on gold substrate with a bolaamphiphile named 16-Mercaptohexadecanoic acid (MHA). Firstly, the samples of gold substrate (blank control), the MHA-modified substrate, and the Aß42-modified substrate were detected by $X$-ray photoelectron spectroscopy (XPS) to track the self-assembly process. Aggregation behaviors of $\mathrm{A} \beta 42$ before and after metallic ions $\left(\mathrm{Zn}^{2+}, \mathrm{Ca}^{2+}, \mathrm{Al}^{3+}\right)$ treatment were monitored by atomic force microscopy (AFM) and the interaction between $A \beta 42$ and metallic ions $\left(\mathrm{Zn}^{2+}, \mathrm{Ca}^{2+}, \mathrm{Al}^{3+}\right)$ was investigated by surface-enhanced Raman Scattering (SERS).
\end{abstract}

Results: The XPS spectra of binding energy of gold substrate (blank control), the MHA-modified substrate, and the A 342 -modified substrate are well fitted with the corresponding monolayer's composition, which indicates that A $\beta 42$ monolayer is well formed. The recorded surface morphology of different experimental groups obtained by AFM showed markedly different nanostructures, indicating occurrence of aggregation events between $A \beta 42$ molecules after adding metal ions to the solution. Compared to the control group, the presence of metallic ions resulted in the increased size of surface structures on the observed 3D topography. Besides, the intermolecular rupture force of $A \beta 42$ increased with the addition of metallic ions. Further study by SERS showed that the Raman strength of $A \beta 42$ changes significantly after the metal cation treatment. A considerable part of the amide bonds interacts with metal cations, leading to a structural change, which is characterized by the weakened $\beta$-fold Raman peak.

Conclusion: The AFM imaging results suggest that aggregation events occurred between $A \beta 42$ molecules with the addition of metal cations. In addition, the results author(s) and the source, provide a link to the Creative Commons licence, and indicate if changes were made. The images or other third party material in this article are included in the article's Creative Commons licence, unless indicated otherwise in a credit line to the material. If material is not included in the article's Creative Commons licence and your intended use is not permitted by statutory regulation or exceeds the permitted use, you will need to obtain permission directly from the copyright holder. To view a copy of this licence, visit http:// creativecommons.org/licenses/by/4.0/. The Creative Commons Public Domain Dedication waiver (http://creativecommons.org/publicdomain/zero/1.0/) applies to the data made available in this article, unless otherwise stated in a credit line to the data. 
of force tests indicate that the presence of metallic ions could promote adhesion between $A \beta 42$ molecules, which is likely to be the trigger for aggregation behavior of $A \beta 42$. Furthermore, the effect of metallic cations on the conformational change of A 342 studied by SERS supported the results obtained by AFM. Taken together, the results showed that the presence of substoichiometric metal cations promotes aggregation behavior between $\mathrm{A} \beta 42$ molecules on the substrate at $\mathrm{pH} 7.4$.

Keywords: $\beta$-Amyloid peptides, Self-assembly monolayers, Atomic force microscopy, Surface-enhanced Raman Scattering

\section{Background}

In recent years, Alzheimer's disease (AD) is paid more and more attention for its terrible influence on the health of the elderly. Amyloid plaques with high density of $\beta$-amyloid peptides $(A \beta)$ in the brain tissue of patients have been reported to be the major pathological feature of AD [1]. It was reported that the concentration of deposited $A \beta$ in the cerebral cortex correlates with the degree of dementia and synaptic loss [2]. Main components of the plaques were studied to be $A \beta 40$ and $A \beta 42$, which are two homologous isomers of $A \beta$ [3]. While $A \beta 40$ is the most abundant homologous isomers ever discovered, $A \beta 42$ has been reported to be the most toxic $[4,5]$. Hence, the article focuses on the aggregation of $A \beta 42$, whose neurotoxicity has essential correlation with the pathology of $\mathrm{AD}[6]$. There remains a key question in the pathology of $\mathrm{AD}$ : what are the risk factors that affect the aggregation of $\mathrm{A} \beta$ ? In recent years, several neurotoxic metal ions were proposed as affecting factors in the misfolding and aggregation processes of $A \beta$ [7]. It has been found through the autopsy of AD patients that abnormally high concentrations of $\mathrm{Zn}^{2+}$ and $\mathrm{Ca}^{2+}$ are present along with $\mathrm{A} \beta$ in the senile plaques of $\mathrm{AD}[8,9]$, where $\mathrm{Al}^{3+}$ is also detected [10].

Exploring the underlying mechanism regulating $A \beta$ aggregation remains challenging and the mechanism of metal cations' effect on $A \beta$ remains elusive. Until now, the lack of study on revealing molecular events of $A \beta$ raised a controversy about whether metal cations are helpful to the aggregation of $A \beta$ molecules. Therefore, a study on aggregation events of $A \beta$ in the presence and absence of metal ions at molecular level would be of great significance in terms of pathology and methodology. In recent years, atomic force microscopy (AFM) has been widely used for studying the interaction between molecules, especially protein-protein interaction [11, 12]. Since the turn of the century, new perspectives have been opened with the advent of AFM in the investigation of biomolecular interactions [13]. Up to now, some research methods have been developed to study protein-protein interactions, such as surface plasmon resonance (SPR) [14], enzyme immunoassay (EIA) [15], surface force apparatus (SFA) [16], and atomic force microscopy (AFM) [17]. Compared with other methods, AFM has the advantage of obtaining images with high spatial resolution and carrying out measurements under near-physiological conditions [18]. Consequently, AFM opens novel avenues for studying pathways of interactions between proteins and makes the study of physical behaviors of proteins achievable. In addition, along with the advantage of obtaining protein molecules' topographies on nanoscale, AFM enables researchers to monitor the aggregation behaviors between $A \beta$ monomers. This study focuses on the effects of several metal ions $\left(\mathrm{Zn}^{2+}, \mathrm{Ca}^{2+}, \mathrm{Al}^{3+}\right)$ on $\mathrm{A} \beta 42$ 
aggregation. The three-dimensional morphology measured by AFM has high spatial resolution. All experiments were carried out under near-physiological conditions and a low ion concentration, closer to physiologically relevant values, is applied. By using AFM, it is achievable to concentrate on what we can find by "looking" at the protein molecules and analyze biological phenomena [19].

However, the main challenge with AFM testing is the sample preparation, especially the stabilization of protein molecules onto the gold substrate. In this study, the possibility of investigating molecular events in physiological solution is realized through a sample preparation method called self-assembly monolayer (SAM), which has been developed over the last two decades and widely applied by biologists and chemists [20, 21]. To achieve SAM chemically, a cleaned gold substrate should be immersed in a solution of thiols (16-Mercaptohexadecanoic acid (MHA)), which is followed by spontaneous reaction between the thiol and gold. Gradually, MHA monolayer on the gold surface with ordered and stable bonds ( $\mathrm{Au}-\mathrm{S}$ bond) is formed. Afterward, the carboxyl terminus of MHA is activated by 1-ethyl-3-(dimethylaminopropyl)carbodiimide hydrochloride (EDC) and $N$-Hydroxysulfosuccinimide (NHS) and then immersed into protein (A 342$)$ solution. Eventually, a stable and ordered monolayer of $A \beta 42$ on the thiol-modified gold surface is formed. The mechanism of mercaptan self-assembly method is illustrated in Fig. 1a.

In order to track the formation of $A \beta$ monolayer, $X$-ray photoelectron spectroscopy (XPS) was employed. The composition characteristics of the gold surface, the A $\beta 42$ monolayer, and the MHA film were studied. Next, we monitored the nanostructure changes of $A \beta 42$ in the presence and absence of metallic ions $\left(\mathrm{Zn}^{2+}, \mathrm{Ca}^{2+}\right.$, $\mathrm{Al}^{3+}$ ) by employing AFM imaging and performed force measurement after $\mathrm{A} \beta 42$ aggregation. What worth mentioning is that $A \beta 42$ molecules must be immobilized on the surface of the gold-coated probe tip and the substrate before force test. In this study, the interaction of $A \beta 42$ monolayers is characterized by rupture force (Fig. 1b) between the probe tip and substrate [22]. Furthermore, the interaction between metallic ions and $A \beta$ is probed and discussed by Surface-Enhanced Raman Scattering (SERS), which is an emerging sample surface analysis technique [23]. The changes of

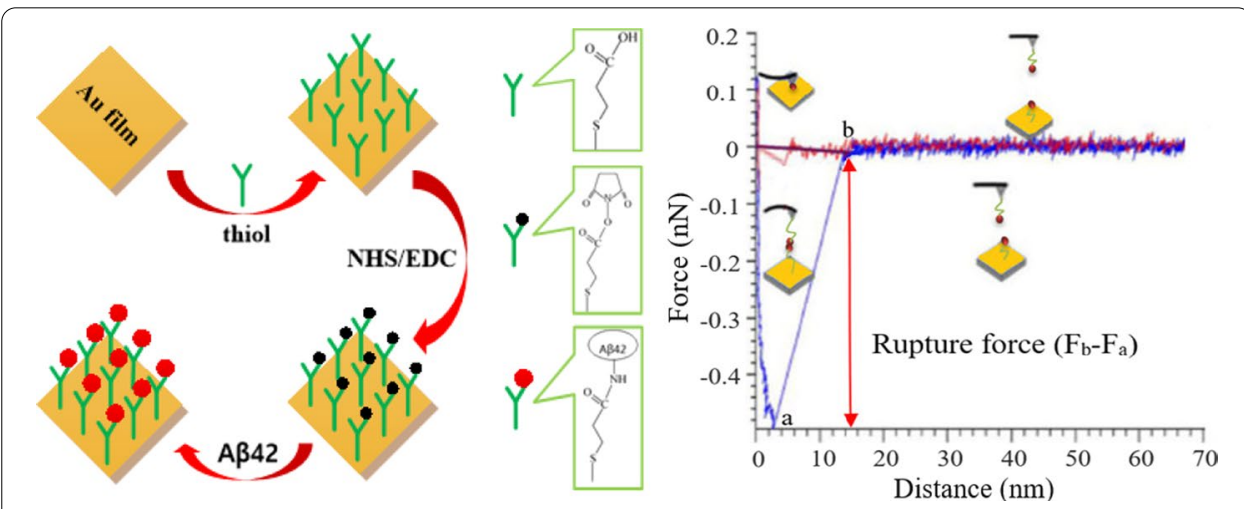

Fig. 1 Experimental setup of AFM. a A schematic diagram of mercaptan self-assembly method, which shows covalent attachment of A 342 on the carboxyl terminal of thiol-modified gold substrate. $\mathbf{b}$ A typical forcedistance curve with recorded rupture force $\left(F_{a}-F_{b}\right)$. A $\beta 42$ is immobilized on the Au-modified mica surface via MHA linker. The counterpart A 42 is immobilized on the MHA functionalized Au-coated tip 
chemical bonds and groups in molecules lead to different molecular rotation or vibration states, which can be judged by the change of Raman scattering light frequency [24]. For proteins, Raman scattering can obtain not only important information about amino acid composition but also secondary structure information, such as $\beta$-sheet and $\alpha$-helix. It has been reported that the Raman cross sections of Au are enhanced to some extent when they adsorb different molecules [25]. Because this effect occurs in the metal adsorbed molecular system, many important processes, such as surface studies, are related to it. The purpose of SERS study is to quantitatively characterize the effect of metal ions on the conformational transition of $A \beta 42$, and to probe the role of these metal ions in the process of abnormal aggregation of $A \beta 42$. Combined with the results of AFM study, the aggregation behavior of $A \beta$ in the absence and presence of metallic ions was elucidated.

\section{Results}

\section{Characterization of bare Gold, MHA Film, and A $\beta 42$ monolayer by XPS}

The surfaces of different samples (blank substrate, MHA films, A 442 monolayer) were investigated by XPS and all measurements should be repeated 3 times for each sample. Full spectrum of elements obtained by XPS showed changed element binding energy of the bare gold, MHA-modified, and the Aß42-modified gold sample. Figure 2 shows the full XPS spectra of the three surfaces, namely, binding energy spectra of bare gold (a), binding energy spectra of MHA (b), and binding energy spectra of A $\beta 42$ monolayer (c). Besides, binding energy spectra of S2p after MHA modification (d) were recorded.

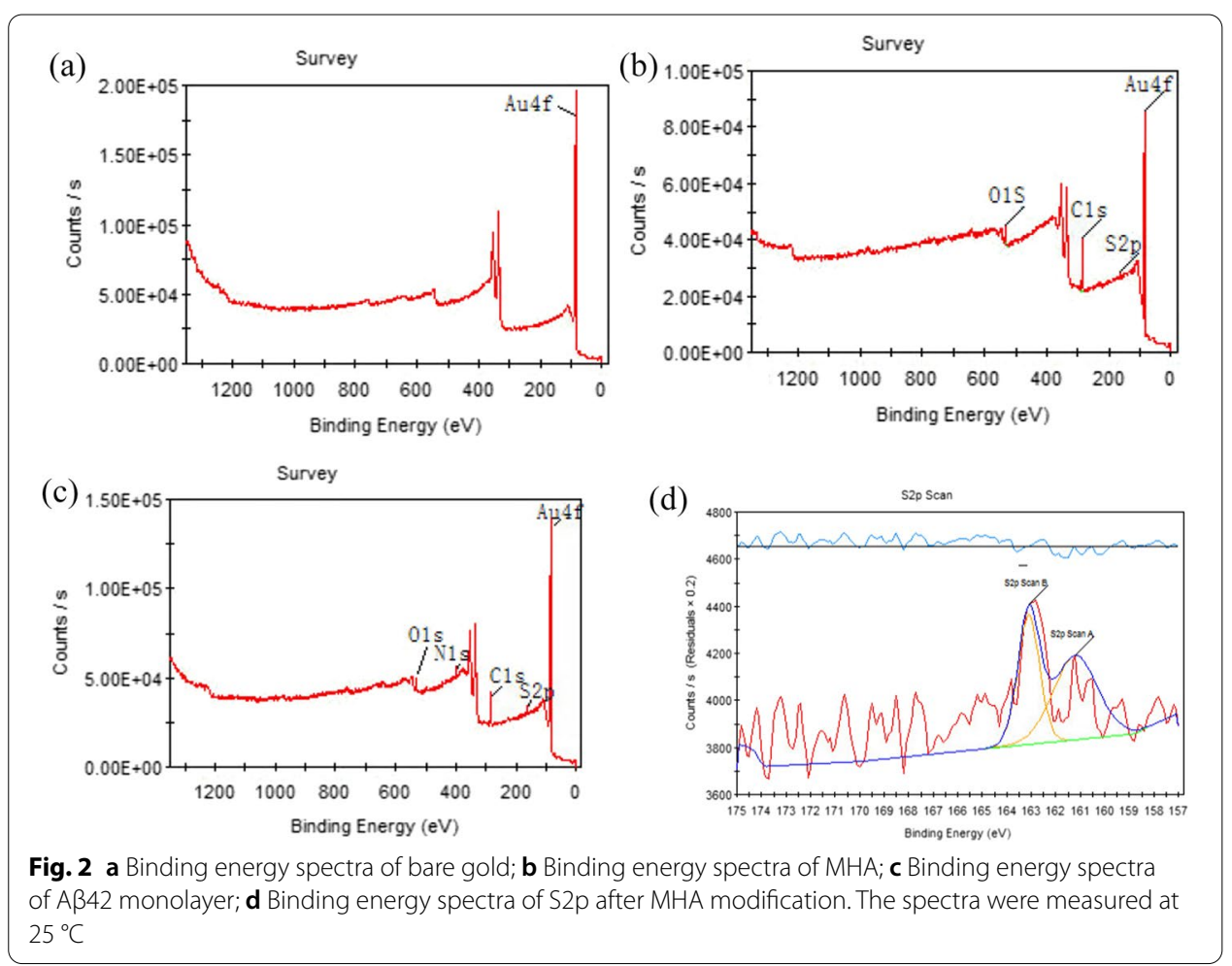




\section{AFM imaging and force measurement}

Figure 3 shows the histogram of average diameter of the nanostructures on the images of the A $\beta 42$ monolayer in blank solution, $10 \mu \mathrm{M} \mathrm{Zn}^{2+}$ solution, $10 \mu \mathrm{M} \mathrm{Ca}^{2+}$ solution, and $10 \mu \mathrm{M} \mathrm{Al}^{3+}$ solutions, respectively. Firstly, a three-dimensional topography of A $\beta 42-$ modified substrate was recorded in PBS by AFM as the control experiment (Fig. 4(a1)). The topography image of A $\beta 42$ monolayer in the absence of metallic cations displayed homogeneous sharp granular-like structure after incubating for $24 \mathrm{~h}$ or $48 \mathrm{~h}$ (Fig. 4(a1)). However, the topography of $\mathrm{A} \beta 42$ monolayer in the presence of $\mathrm{Zn}^{2+}, \mathrm{Ca}^{2+}$, and $\mathrm{Al}^{3+}$ showed irregular smooth spheroid-like structures after 24 h (Fig. 4(b1), (c1), (d1)). With the increase of incubation time to $48 \mathrm{~h}$, globular features were still observed on the surface of A 342 monolayer treated with metallic cations (Fig. 4(b2), (c2), (d2)).

The sizes of the nanostructures on the surface of each sample were characterized by average diameter by using software analysis (as shown in Fig. 5). The average size of the observed nanostructure in control group was calculated to be $43.12 \mathrm{~nm}$ at the incubation time of $24 \mathrm{~h}$ (Fig. 5, blue bar) and $44.32 \mathrm{~nm}$ at the incubation time of $48 \mathrm{~h}$ (Fig. 5, red bar), respectively. After treated with $\mathrm{Zn}^{2+}$, the average size of the surface nanostructures increased to $65.87 \mathrm{~nm}$ at the incubation time of $24 \mathrm{~h}$ and $76.13 \mathrm{~nm}$ at the incubation time of 48 h, respectively. For A $\beta 42$ monolayer treated with $\mathrm{Ca}^{2+}$, the average size of the surface nanostructures was calculated to be $56.31 \mathrm{~nm}$ at the incubation time of $24 \mathrm{~h}$ and $65.34 \mathrm{~nm}$ at the incubation time of $48 \mathrm{~h}$, respectively. It is worth noting that in the presence of $\mathrm{Al}^{3+}$, the average size of nanostructures observed on the image significantly increased to $72.67 \mathrm{~nm}$ at the incubation time of $24 \mathrm{~h}$ and $89.12 \mathrm{~nm}$ at the incubation time of $48 \mathrm{~h}$.

In addition, the surface roughness of each topography is characterized by an average roughness $\left(R_{\mathrm{n}}\right)$ (shown in Table 1 ). By applying software analysis, it was found

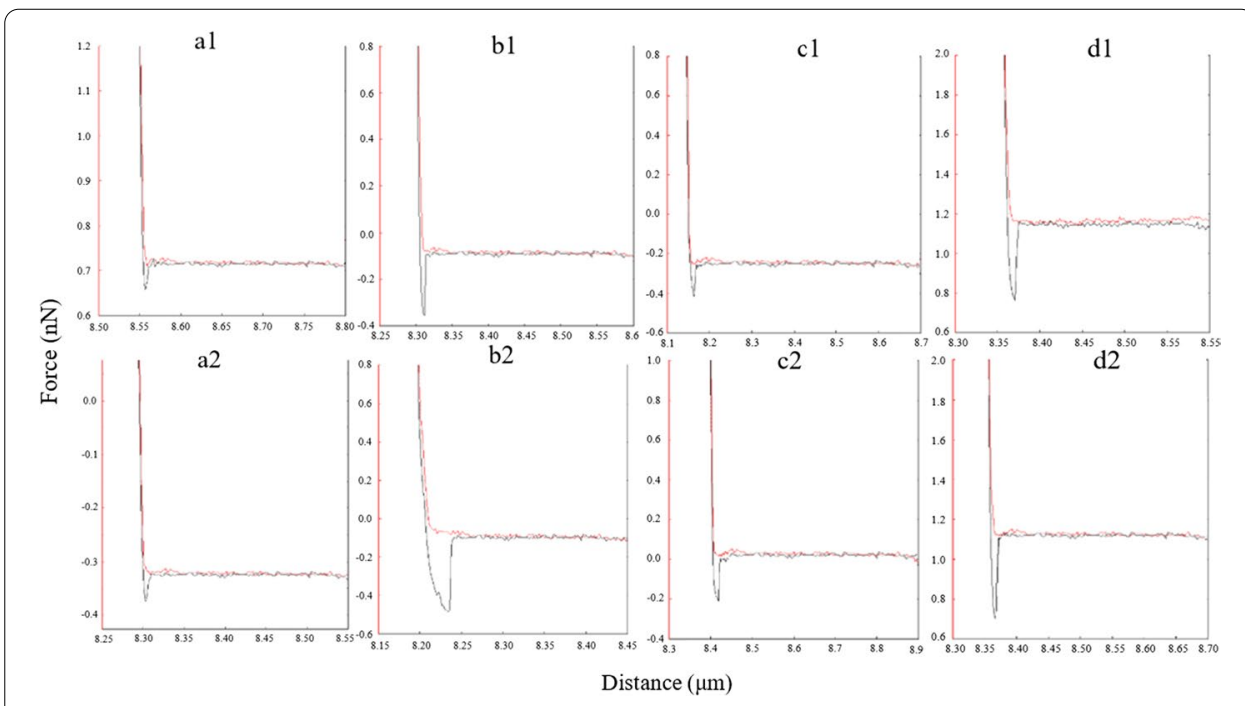

Fig. 3 Representative force-distance curves measured in different experimental groups a1 A 342 monolayer incubated in blank solution for $24 \mathrm{~h}$; a2 A 42 monolayer incubated in blank solution for 48 h; b1 A 342 monolayer incubated in the presence of $Z^{2+}$ for $24 h ; \mathbf{b} 2 \mathrm{~A} \beta 42$ monolayer incubated in the presence of $\mathrm{Zn}^{2+}$ for 48 h; c1 A 442 monolayer incubated in the presence of $\mathrm{Ca}^{2+}$ for $24 \mathrm{~h} ; \mathbf{c 2} \mathrm{A} \beta 42$ monolayer incubated in the presence of $\mathrm{Ca}^{2+}$ for $48 \mathrm{~h} ; \mathbf{d} \mathbf{1} \mathrm{A} \beta 42$ monolayer incubated in the presence of $\mathrm{Al}^{3+}$ for $24 \mathrm{~h} ; \mathbf{d} \mathbf{2} \mathrm{A} \beta 42$ monolayer incubated in the presence of $\mathrm{Al}^{3+}$ for $48 \mathrm{~h}$. (red line--approach trace, blue line--retract trace) 


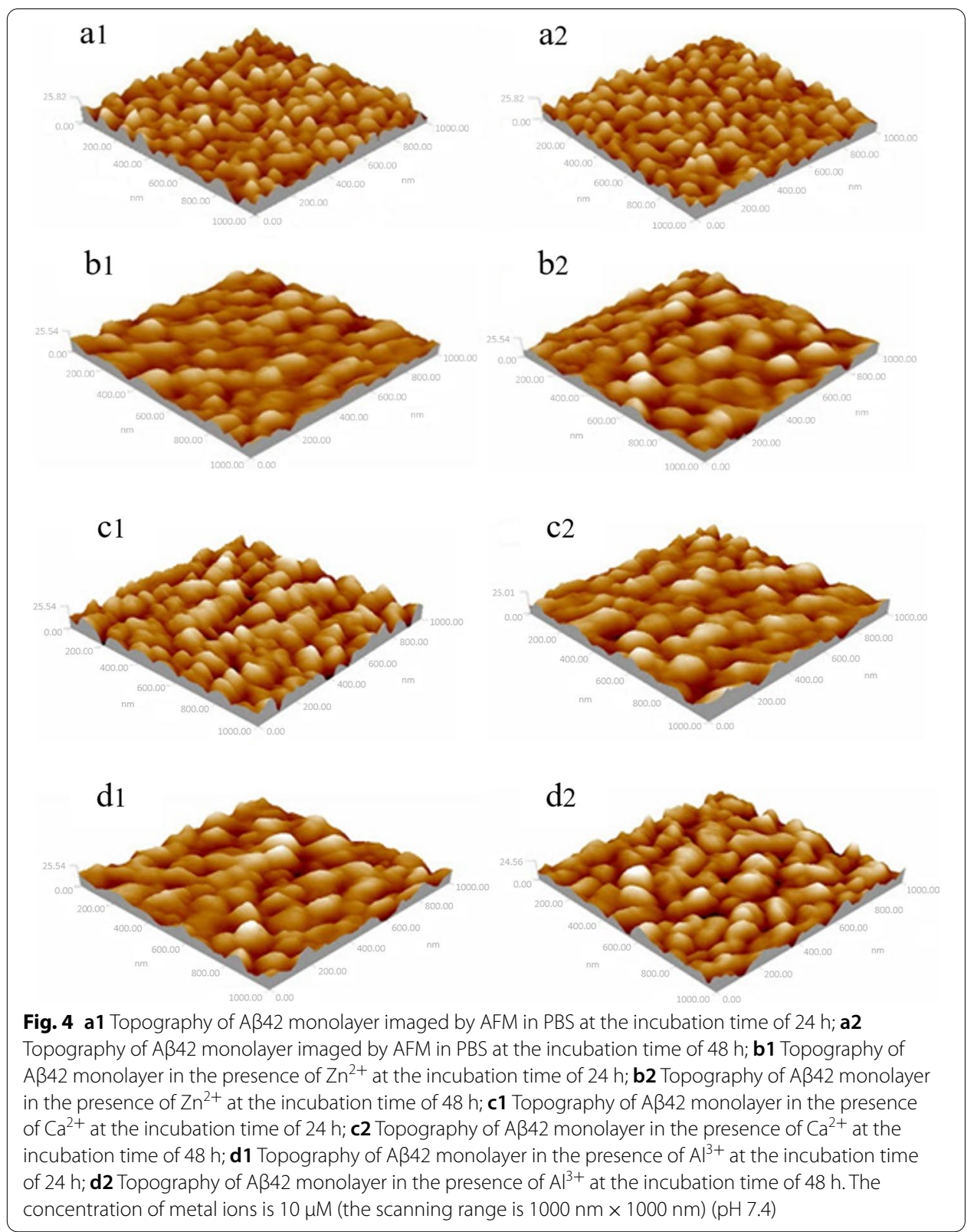

that the surface roughness of $A \beta 42$ monolayer in different experimental groups varied significantly. The change of surface particles can be characterized by average roughness $R_{\mathrm{n}}$. The results showed that the average roughness of control group (in physiological solution) was 1.958 at the incubation time of $24 \mathrm{~h}$ and little change of $R_{\mathrm{n}}$ was observed at the incubation time of $48 \mathrm{~h}$. For $\mathrm{A} \beta 42$ monolayer incubated in $10 \mu \mathrm{M}$ $\mathrm{Zn}^{2+}, \mathrm{Ca}^{2+}$ and $\mathrm{Al}^{3+}$ solutions for $24 \mathrm{~h}, R_{\mathrm{n}}$ was calculated to be $1.762,1.82$, and 1.672, respectively. For $\mathrm{A} \beta 42$ monolayer incubated in $10 \mu \mathrm{M}$ in $10 \mu \mathrm{M} \mathrm{Zn}^{2+}, \mathrm{Ca}^{2+}$, and $\mathrm{Al}^{3+}$ solutions for $48 \mathrm{~h}$, the $R_{\mathrm{n}}$ was calculated to be $1.54,1.622$, and 1.412 , respectively.

Furthermore, the effect of metallic cations on $A \beta 42$ interaction was investigated by measuring the rupture force in different conditions. Representative force-distance 


\section{$\square 24 \mathrm{~h} \nabla 48 \mathrm{~h}$}

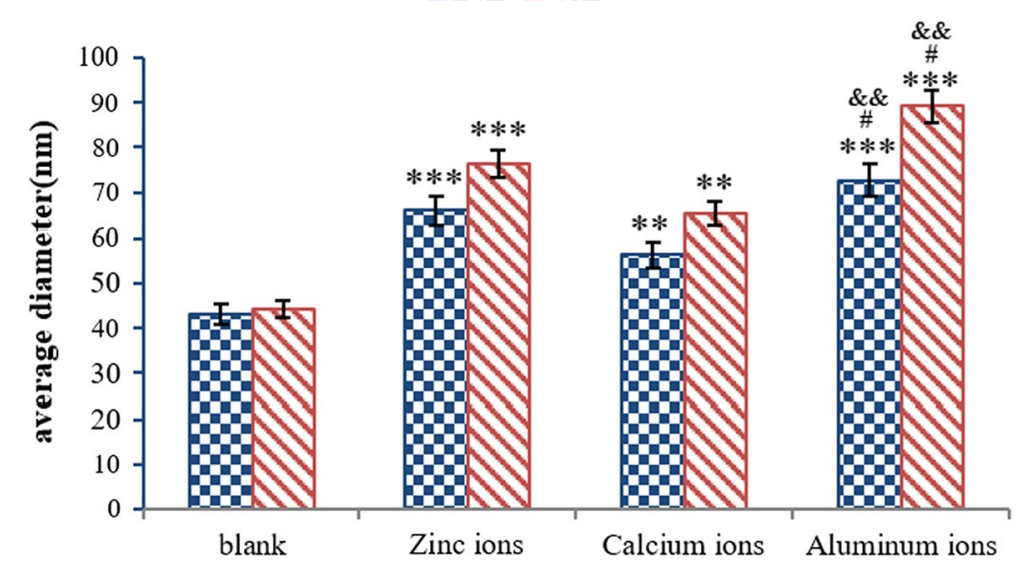

Fig. 5 Average particle size of $A \beta 42$ monolayer in the absence and presence of metallic ions $\left(\mathrm{Zn}^{2+}, \mathrm{Ca}^{2+}\right.$ and $\left.\mathrm{Al}^{3+}\right)$ at different incubation time points. All experiments were performed ten times $(n=10)$. ${ }^{* *} P<0.001$, ${ }^{*} \mathrm{P}<0.005$ vs. control; ${ }^{P} P<0.01$ vs. PBS $+\mathrm{Zn}^{2+} ;$ \&\& $P<0.005$ vs. $\mathrm{PBS}+\mathrm{Ca}^{2+}$

Table 1 Average roughness $\left(R_{n}\right)$ of A 42 monolayer in the absence and presence of metallic ions at different incubation time points

\begin{tabular}{llll}
\hline sample & $R_{n}$ & sample & $R_{n}$ \\
\hline Control(24 h) & 1.958 & Control(48 h) & 1.954 \\
$\mathrm{Zn}^{2+}(24 \mathrm{~h})$ & 1.762 & $\mathrm{Zn}^{2+}(48 \mathrm{~h})$ & 1.54 \\
$\mathrm{Ca}^{2+}(24 \mathrm{~h})$ & 1.82 & $\mathrm{Ca}^{2+}(48 \mathrm{~h})$ & 1.622 \\
$\mathrm{Al}^{3+}(24 \mathrm{~h})$ & 1.672 & $\mathrm{Al}^{3+}(48 \mathrm{~h})$ & 1.412 \\
\hline
\end{tabular}

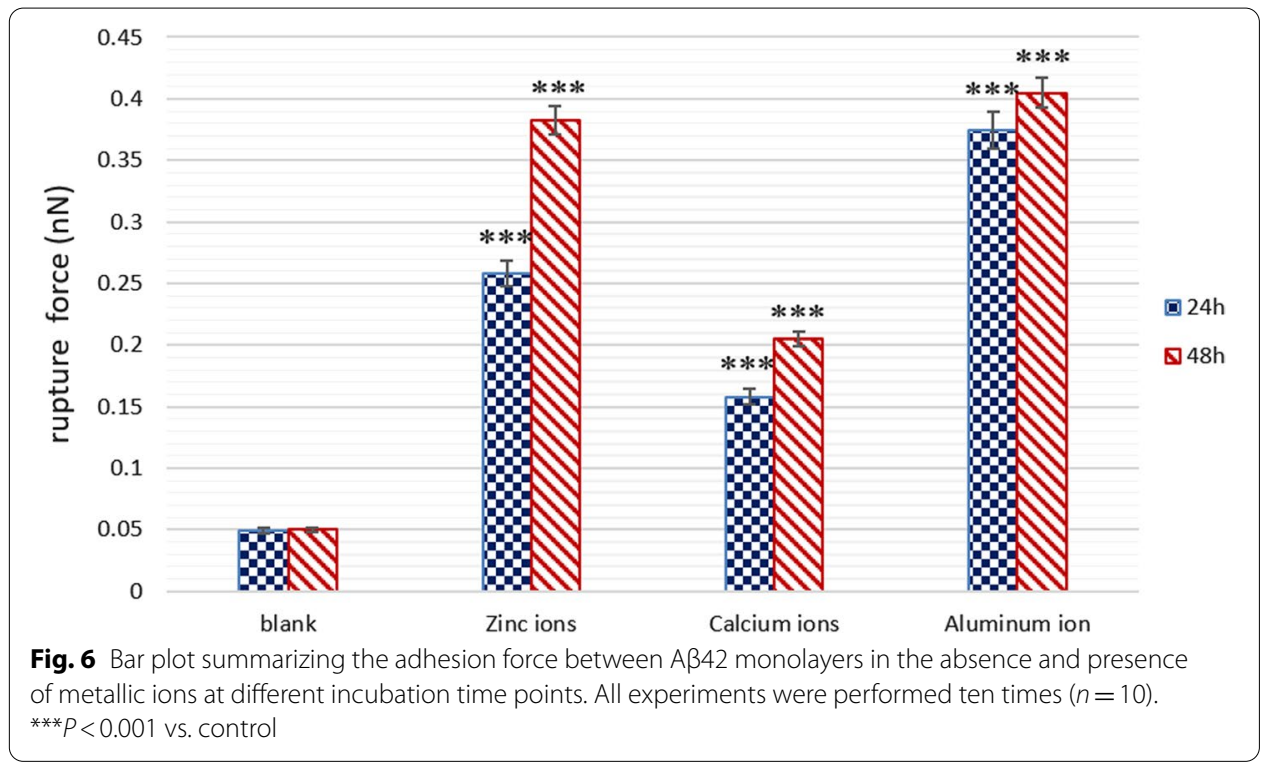

curves recorded in different groups are shown in Fig. 3. The force measurements were repeated 10 times for each group. Subsequently, the average rupture force for each sample is analyzed and shown in Fig. 6, which provides a clear comparison between 
the control group and experimental groups. The result of force test showed that in blank solution, the rupture force between $\mathrm{A} \beta 42$ monolayers was $0.049 \mathrm{nN}$ at the incubation time of $24 \mathrm{~h}$ and $0.05 \mathrm{nN}$ at the incubation time of $48 \mathrm{~h}$, respectively. Whereas in the presence of $\mathrm{Zn}^{2+}$ the rupture force between $A \beta 42$ monolayers was observed to increase to $0.258 \mathrm{nN}$ at the incubation time of $24 \mathrm{~h}$ and $0.383 \mathrm{nN}$ at the incubation time of $48 \mathrm{~h}$, in the presence of $\mathrm{Ca}^{2+}$ the rupture force between $\mathrm{A} \beta 42$ monolayers was observed to increase to $0.158 \mathrm{nN}$ at the incubation time of $24 \mathrm{~h}$ and $0.205 \mathrm{nN}$ at the incubation time of $48 \mathrm{~h}$. Moreover, in the presence of $\mathrm{Al}^{3+}$, significantly increased rupture force was recorded $(0.375 \mathrm{nN}$ at the incubation time of $24 \mathrm{~h}$ and $0.405 \mathrm{nN}$ at the incubation time of $48 \mathrm{~h}$ ). In conclusion, the results of force test showed that the interaction (adhesion) between $A \beta 42$ monolayers increased with the addition of metallic ions in solution.

\section{Results of SERS}

In general, the enhancement of the surface signal is 106 times, which is equivalent to the amplification of the surface monolayer to more than one million layers. Therefore, the advantage of SERS is that it can avoid the signal interference caused by the same substance in the solution, and obtain high-quality surface molecular vibration and rotation signals, which is of great significance for a detailed understanding of the interaction mode between molecules (such as metal ions) and self-assembled monolayers and the structural changes of molecules. Since the discovery of SERS, it has been successfully applied in many fields, such as chemistry and biology.

Above all, stable SERS signal is of great significance for accurate analysis results. Hence, the SERS properties of the obtained A $\beta 42$-modified substrates were evaluated in different metal ion environments. In order to investigate the stability of Raman measurement results, the changes of SERS spectra of A $\beta 42$ molecular layer were recorded under continuous laser irradiation. As shown in Fig. 7, when different integral time was set, no obvious change in the peak shape of Raman spectrum curves for different samples was

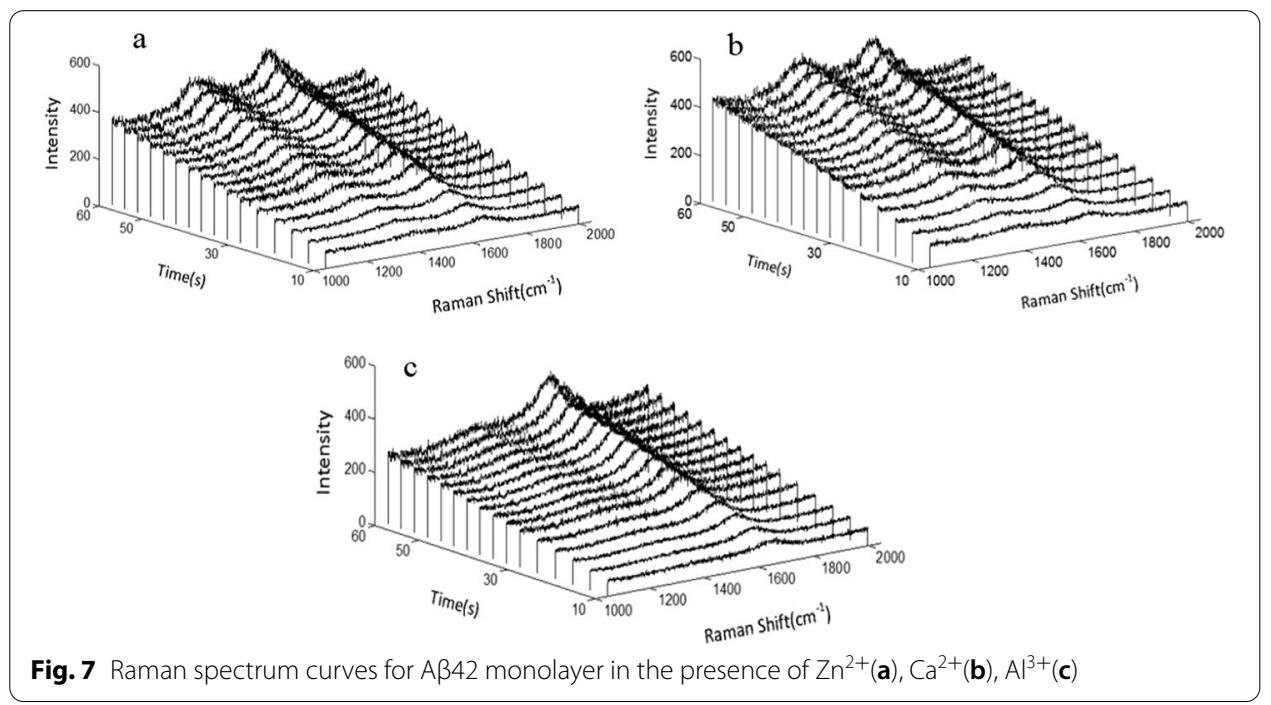


observed, which means the $A \beta 42$ monolayer in these three metal ion solutions has good stability under continuous laser irradiation.

In Fig. 8, curve A stands for the Raman spectrum of the blank control group and curve B stands for the experimental group. The results indicated that $\beta$-fold (peak at $1669 \mathrm{~cm}-1$ ) and Amide II (peak at $1375 \mathrm{~cm}-1$ ) are the characteristic structure for the natural conformation of $\mathrm{A} \beta 42$. With the addition of $\mathrm{Zn}^{2+}$, the peak intensity of the $\beta$-folded conformation at $1669 \mathrm{~cm}-1$ and amide II band at $1375 \mathrm{~cm}-1$ was weakened to a certain extent, respectively (Fig. 8(a)). Moreover, in blank control group, the Raman peak signal at $1375 \mathrm{~cm}-1$ was determined to be stronger than that at $1669 \mathrm{~cm}-1$, which means the vibration attributed to $\mathrm{N}-\mathrm{H}$ is greater than that attributed to $\beta$-fold. On the contrary, the signal intensity of Amide II $(1375 \mathrm{~cm}-1)$ was greatly weakened after adding $\mathrm{Zn}^{2+}$, which is lower than that of $\beta$-fold $(1669 \mathrm{~cm}-1)$. As shown in Fig. 8 (b), the addition of $\mathrm{Ca}^{2}$ ${ }^{+}$also caused a structural change of $A \beta 42$, which is characterized by the reduced Raman intensity of Amide II from 156.13 to 115.36, and the reduced Raman intensity of $\beta$-fold decreased from 144.669 to 117.76 . It is worth noting that the Raman peak of Amide II at $1375 \mathrm{~cm}^{-1}$ was greatly weakened and almost disappear, and the intensity of the $\beta$-fold peak at $1669 \mathrm{~cm}^{-1}$ was also decreased compared with the blank control group, indicating that a considerable part of amide bonds in $A \beta 42$ molecule probably interacted with $\mathrm{Al}^{3+}$ which resulted in a conformational change (Fig. 8(c)). Furthermore, the change of molecular conformation was evaluated by the Raman intensity ratio $\left(I_{1375} / I_{1669}\right)$ (as shown in Fig. 9).

\section{Discussion}

\section{Preparation of chemically immobilized $A \beta 42$ monolayers}

It is of crucial importance to consider immobilization carefully for the sensitivity and reproducibility of bioassays. Self-assembly monolayer (SAM), which is reliable for protein immobilization, is a topic of current interest in biological studies. SAM method can be used for self-assembly of protein molecules without altering the stability and activity of protein [26]. It has been studied that thiol concentration of $1 \mathrm{mM}$ and immersion time of $24 \mathrm{~h}$ are befitting for the formation of Mercaptan molecular film [27]. Besides, MHA with a proper length of the chain serves as a spacer to minimize the interference from gold substrate [28].
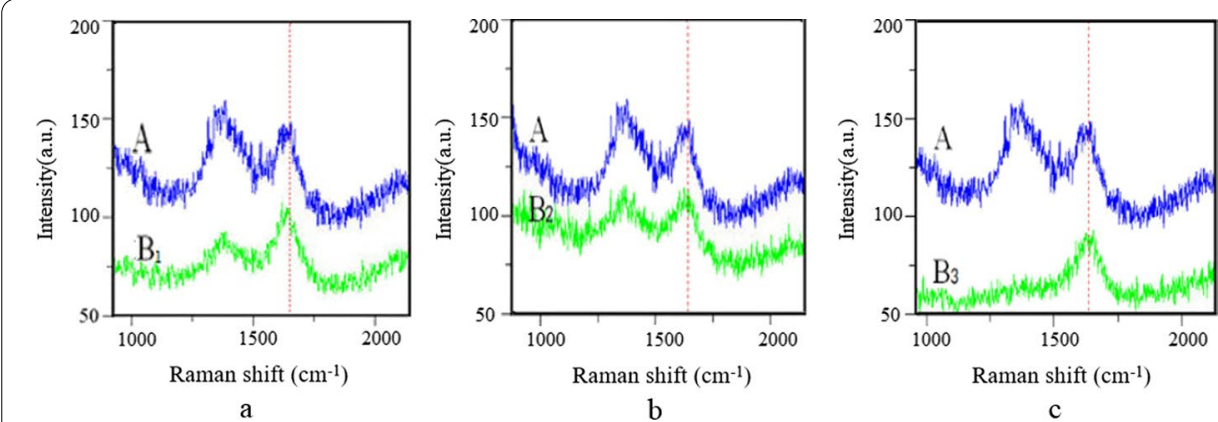

Fig. 8 Raman Spectra about various metallic ions effects on A 442 (integration time for $10 \mathrm{~s}$ ), with line $A$ as control group; $\mathbf{a}$ in the presence of $\mathrm{Zn}^{2+}, \mathbf{b}$ in the presence of $\mathrm{Ca}^{2+}, \mathbf{c}$ in the presence of $\mathrm{Al}^{3+}$ 


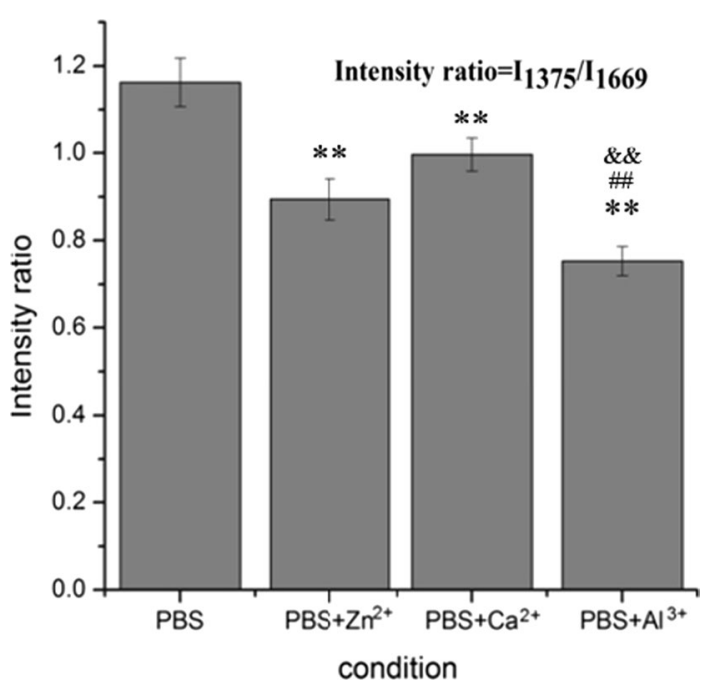

Fig. 9 Intensity ratio $I_{1375} / I_{1669}$ of $A \beta 42$ molecule in the absence and presence of metal cations (integration time for 10 s). All experiments were performed in triplicates $(n=3)$. ${ }^{*} P<0.01$ vs. control (PBS); ${ }^{\# \#} P<0.01$ vs. $\mathrm{PBS}+\mathrm{Zn}^{2+} ; \& \& \mathrm{P}<0.01 \mathrm{vs}$. PBS $+\mathrm{Ca}^{2+}$

We monitored the self-assembled processes by X-ray photoelectron spectroscopy (XPS) to ensure that A $\beta 42$ was successfully modified on the surface of the gold substrate. Electron emission can be observed when the sample is exposed to electromagnetic waves with short enough wavelengths, i.e., high photon energy. This phenomenon is called photoelectric effect or photoionization because of the presence of observable photocurrents. In this process, the binding energy of material can be expressed by the following equation:

$$
E_{k}=h n-E_{b}-f_{s},
$$

$E_{k}$ represents the kinetic energy of photoelectrons (in $\mathrm{eV}$ ); $h v$ represents the energy of photons in the X-ray source (in $\mathrm{eV}$ ); $E_{\mathrm{b}}$ represents the binding energy in the specific orbit of an atom (in $\mathrm{eV}$ ); $\phi_{\mathrm{s}}$ represents the work function of the spectrometer (in $\mathrm{eV})$.

Figure 2 shows that the elements on the surface of the three samples are identical to the modified molecules during self-assembly. XPS results demonstrated that for the MHA film and the A 342 monolayer, no noticeable chemical elements in addition to the ones expected based on their chemical constitution were found on the sample. The peak values of Au4f binding in the XPS spectra of blank substrate are $86.7 \mathrm{eV}$ and $83.9 \mathrm{eV}$, respectively, which are consistent with the standard spectra. The peak values of Au4f binding shifted to 87.9 and $90.8 \mathrm{eV}$ after the MHA molecule was modified on the surface of gold film. The formation of Au-S bond should be the cause of the binding energy shift of Au4f. What is more, peak position of the S2p binding energy spectrum (Fig. 2d) of the MHA film is lower than $164 \mathrm{eV}$, indicating that there is no unbounded MHA molecule on the sample surface [29]. There are two main peaks in the binding energy spectrum of S2p. The peak at $161.2 \mathrm{eV}$ may 
be due to the bond between MHA and Au, which reduces the binding energy of S2p [30]. The peak at $161 \mathrm{eV}$ may be attributed to the C-S bond [31]. The results suggest that the immobilization of $A \beta 42$ on the gold substrate is successful.

\section{The aggregation behavior of $A \beta 42$ observed by AFM}

As for topography images recorded by AFM contact mode, it is worth noting that broaden effect introduced by the probe tip will enlarge the particle size (as illustrated in Fig. 10). Based on electron micrographs, a round shape for the probe tip is assumed. A half sphere structure is assumed as an $A \beta 42$ molecule immobilized on the substrate. When a tip scans over the sample surface, it constantly approaches an elevation from the side of $\mathrm{A} \beta 42$ (or its aggregates) contour. The elevation with its outer edge will be recorded as the morphology of $A \beta 42$ (or its aggregates) before the center of a probe tip reaches the real point where the elevation starts [32].

The average diameter of the nanostructures $(D=2 x)$ on the topography images of the A $\beta 42$ monolayer in the absence and presence of metallic ions was analyzed, respectively (as shown in Fig. 5). The average size of the observed nanostructure on the surface of $A \beta 42$ monolayer in blank solution (PBS) at the incubation time of $24 \mathrm{~h}$ was found to be $43.12 \mathrm{~nm}$ (Fig. 5, blue bar in blank group). At the incubation time of $48 \mathrm{~h}$, little change in particle diameter was observed. Considering the broaden effect according to equation in Fig. 8 for a tip of $R=25 \mathrm{~nm}$ (data given by the tip manufacturer), this real size for nanostructures in blank group is calculated to be $\sim 16 \mathrm{~nm}$, which is close to the theoretical estimation for size of A $\beta 42$ oligomers [33]. With addition of $\mathrm{Zn}^{2+}$, the average diameter of the observed nanostructures increased to $65.87 \mathrm{~nm}$ at the incubation time of $24 \mathrm{~h}$ and $76.13 \mathrm{~nm}$ at the incubation time of $48 \mathrm{~h}$, respectively. Considering the tip broaden effect, real size of $\mathrm{A} \beta 42$ aggregates is calculated to be $\sim 32 \mathrm{~nm}$ at the incubation time of $24 \mathrm{~h}$ and $\sim 40 \mathrm{~nm}$ at the incubation time of $48 \mathrm{~h}$, which is more than double of the size of aggregates observed in blank group, indicating that $\mathrm{Zn}^{2+}$ promoted the mutual aggregation between $\mathrm{A} \beta 42$ molecules on the substrate. Compared to blank group, the real size of nanostructures on $\mathrm{A} \beta 42$ monolayer in the presence of $\mathrm{Ca}^{2+}$ increased to $\sim 25 \mathrm{~nm}$ at the incubation time of $24 \mathrm{~h}$ and $\sim 32 \mathrm{~nm}$ at the incubation time of $48 \mathrm{~h}$, suggesting that the observed

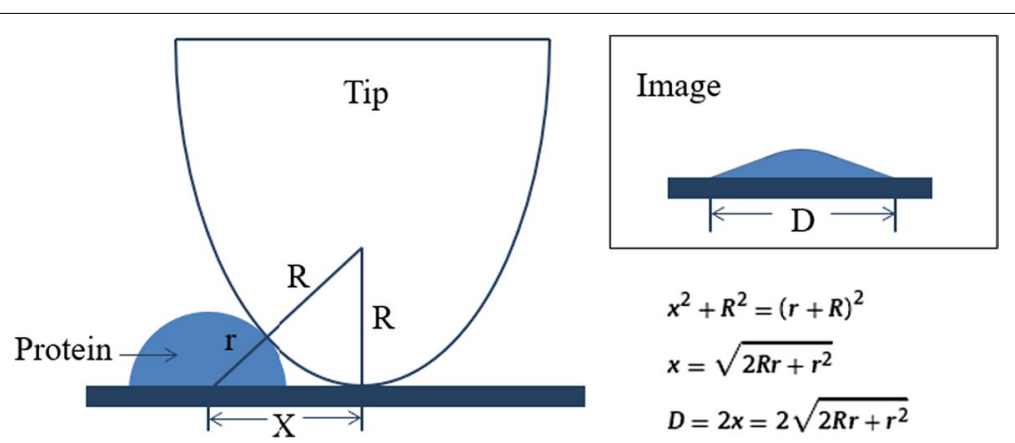

Fig. 10 The broaden effect brought by AFM tip. $R$ represents the tip radii, $r$ represents the real width of protein structure, $x$ and $D$ represent the apparent widths of protein structure, respectively. The final recorded image with a broadened size is shown at the upper-right of the figure. The calculation formula is shown in the lower right corner 
nanostructures in $\mathrm{Ca}^{2+}$ group are $\mathrm{A} \beta 42$ aggregates with higher aggregation levels. In addition, the real size of nanostructures observed in $\mathrm{Al}^{3+}$ group is the largest ( $\sim 40 \mathrm{~nm}$ at the incubation time of $24 \mathrm{~h}$ and $\sim 52 \mathrm{~nm}$ at the incubation time of $48 \mathrm{~h}$ ), which is more than three times of the size of nanostructures in blank group, indicating that $\mathrm{A} \beta 42$ aggregation behaviors were promoted by $\mathrm{Al}^{3+}$. This observed size enlargement phenomenon suggest that more $A \beta 42$ molecules react with neighboring $A \beta 42$ molecules and formed $A \beta 42$ aggregates due to the addition of metallic ions. In addition, combined with the mechanical test results, it can be further inferred that the observed aggregation behavior of $A \beta 42$ molecules is a result of the increase in rupture force (adhesion) between A $\beta 42$ molecules in the presence of metallic cations.

Moreover, it can be found that with the addition of metallic ions, the decrease of $R_{n}$ occurred and $R_{n}$ of $A \beta 42$ monolayer in the presence of metallic ions also decreased in varying degrees with the increase of incubation time. We believe that the aggregation of A 42 particles leads to the collapse of molecular morphology, followed by more and more covered intermolecular gaps, eventually resulting in the decrease of $R_{n}$.

Based on these findings, it can be suggested that in the presence of metallic ions, the aggregation behavior of $A \beta 42$ was induced to varying degrees. In other words, the presence of metal ions leads to disorder and clumping on the surface of $A \beta 42$ monolayer. What is more, stable aggregation state was observed during the experiment with the extending of incubation time. The results indicated that the addition of $\mathrm{Zn}^{2+}, \mathrm{Ca}^{2+}$, and $\mathrm{Al}^{3+}$ drastically destabilized A $\beta 42$ and stabilized aggregation of $\mathrm{A} \beta 42$. The result is consistent with the mode proposed in Alies' paper [34]. Besides, the aggregation state of $\mathrm{A} \beta 42$ in $10 \mu \mathrm{M} \mathrm{Zn}^{2+}, \mathrm{Ca}^{2+}$, and $\mathrm{Al}^{3+}$ solution differed in size of nanoparticles imaged by AFM. In conclusion, AFM imaging and force results showed large amounts of heterogeneous and conglobate-shaped aggregates were produced in the presence of metallic ions and the aggregation state of $A \beta 42$ is stable due to the increased adhesion between $A \beta 42$. The influence of different kinds of metal ions on the process of $A \beta 42$ shows some differences, which may be attributed to the following reasons: (1) different charge amount, different molar ratio of $\mathrm{A} \beta 42$ to metal ions; (2) action modes and action sites on the A $\beta 42$ peptide chain are different in the presence of different metal cations.

\section{SERS analysis}

As shown in Fig. 7, the addition of different metallic ions leads to the decrease of the Raman strength ratio of I1 375/I 1669 to varying degrees. In comparison, $\mathrm{I}_{1375} / \mathrm{I}_{1669}$ of $\mathrm{A} \beta 42$ monolayer in the presence of $\mathrm{Al}^{3+}$ is the lowest, which indicates that $\mathrm{Al}^{3+}$ make the greatest effect on the conformation change of $A \beta 42$. The result is consistent with Banks's study, suggesting that $\mathrm{Al}^{3+}$ can stabilize the aggregation structure of $\mathrm{A} \beta$ to a greater extent [35]. These results indicate that the main binding site of metallic ions in the process of $A \beta 42$ aggregation should be the amide group of $A \beta 42$ peptide chain $(\mathrm{N}-\mathrm{H}$ bond) and the presence of metallic ions has a significant influence on the folding conformation of $\mathrm{A} \beta 42$ molecule.

The nanostructures with aggregation state on the surface in the presence of metallic ions is consistent with the results obtained by SERS. Based on these results, it can be inferred the presence of metallic ions plays a vital role in the occurrence of the 
abnormal aggregation events of $A \beta 42$. The implications of this phenomenon are as follows: misfolding of $A \beta$ conformation at the early stage leads to a destabilization and the interaction between metal cations and $A \beta$ results in a conformational change of $A \beta$, which promotes formation of aggregates.

\section{Conclusion}

A study of aggregation events between A 342 immobilized on MHA monolayer in the absence and presence of metallic ions by AFM imaging and SERS analysis is presented in this paper. The topographic images of $A \beta 42$ monolayer either in the absence of metallic ions or in the presence of metallic ions $\left(\mathrm{Zn}^{2+}, \mathrm{Ca}^{2+}\right.$, and $\left.\mathrm{Al}^{3+}\right)$ show significantly different surface structures. The obtained three-dimensional surface topography of A 442 monolayer show more pronounced state of aggregation in physiological solutions with added metal ions, which is characterized by the enlargement of nanoparticle sizes on the surface. The imaging results suggest that aggregation events occurred between A $\beta 42$ molecules with the addition of metal cations. Furthermore, the effect of metal cations on the conformational change of A $\beta 42$ was studied by SERS, which further supported the results obtained by AFM imaging. It can be inferred that the presence of metallic ions induces structural changes in $A \beta 42$ and increases the intermolecular forces (adhesion) of $A \beta 42$ and it is the increase of adhesion force that leads to a stable structure of $A \beta 42$ oligomers and continuous molecular aggregation. These results, therefore, suggest that the presence of metallic ions plays a crucial role in the accelerated aggregation behavior of $A \beta 42$. It is rational to assume that to block the effects from metal cations or obstruct the interaction between $A \beta$ and metal cations may have great potential in new drug design for AD.

\section{Methods}

\section{Materials}

Metal salts used in this work are chlorides $\left(\mathrm{Zncl}_{2}, \mathrm{Cacl}_{2}\right.$, and $\left.\mathrm{Alcl}_{3} \cdot 6 \mathrm{H}_{2} \mathrm{O}\right)$, manufactured by Sigma Aldrich Chemical Co. All chemicals were used as received. Phosphatebuffered saline (PBS, pH 7.4) and absolute ethyl alcohol (guaranteed grade) were produced by Merck Co. Ultrapure water was made by Millipore purification system. 1-Ethyl-3-(dimethylaminopropyl)carbodiimide hydrochloride (EDC), N-hydroxysulfosuccinimide (NHS), and 16-mercaptohexadecanoic acid (MHA) are made by Sigma Aldrich Chemical Co. The amyloid peptides used in this work (A $\beta 42)$ were obtained from AnaSpec (USA).

\section{Formation of protein films}

\section{Preparation of gold film}

In this experiment, vapor deposition method was applied to obtain the film of gold particles. First of all, a single layer of mica was gently peeled off in a sterile operating box by using a tweezer and the mica was then immediately placed in the radiant tube heater. Using a radiator heater, mica plates were heated to $325^{\circ} \mathrm{C}$ for $2 \mathrm{~h}$ prior to deposition. After that, the preheated mica plate was moved into a turbo evaporator, where 
gold particle spray film deposited on the mica plate in high vacuum (at $\sim 10^{-7}$ Torr). The velocity of evaporation is limited within the range of $0.1-0.3 \mathrm{~nm} / \mathrm{s}$. The thickness of gold granular film is about $200 \mathrm{~nm}$. In addition, a chromium film was deposited between the gold and the surface of mica to increase the adherence. Finally, the obtained gold film was annealed in $\mathrm{H}_{2}$ flame for one minute. Finally, the Au-coated mica was divided into small squares of $1 \times 1 \mathrm{~cm}^{2}$.

Before use, the prepared Au-coated substrates were immersed in piranha solution (v/v $\mathrm{H}_{2} \mathrm{SO}_{4}: \mathrm{H}_{2} \mathrm{O}_{2}=3: 1$ ) for 30 min to remove organic pollutants on the surface. The gold surface was then washed three times by absolute ethyl alcohol and ultrapure water in turn. At last, the surface of Au-coated substrate was dried in nitrogen to avoid any pollution. The surface of bare gold substrate was characterized by XPS.

\section{Formation of MHA film}

MHA was dissolved in an ethanol solution at a concentration of $1 \mathrm{mM}$. After that, the gold substrate was immersed into MHA solution to form MHA membrane spontaneously. Ultrasonic cleaning was applied to remove unbound MHA molecules. Subsequently, the SAM film was irrigated by absolute ethyl alcohol and ultrapure water successively. Finally, it is necessary to dry the MHA film in nitrogen immediately. The sample of MHA monolayer was characterized by XPS.

\section{Aß42 immobilization onto the MHA film}

The carboxyl groups at the end of the MHA film reacts with the amino groups of lysine in A 442 molecule [36, 37]. Taking advantage of this principle, steady A $\beta 42$ monolayer can be acquired [38]. The A $\beta$ protein was dissolved in a physiological solution (PBS), which was freshly prepared according to standard method. It should be noted that MHA film were activated for $1 \mathrm{~h}$ at normal temperature using the method mentioned above. Afterward, the activated MHA film was rinsed as mentioned above and then immersed in $10 \mu \mathrm{M} \mathrm{A} \beta 42$ solution and stored in refrigerator at $4^{\circ} \mathrm{C}$ for $12 \mathrm{~h}$. At last, the $\mathrm{A} \beta 42 \mathrm{film}$ was prepared. Besides, the $A \beta 42$-modified substrates should be rinsed three times by ultrapure water and dried in nitrogen before testing. This step is to remove free protein molecules from the surface of the substrate. The surface of $A \beta 42$ monolayer was characterized by XPS.

XPS

XPS experiments were conducted on a PHI Quantera SXM photoelectron spectrometer, which is equipped with an X-ray radiation source $(\mathrm{Al} \mathrm{K \alpha}, 1486.6 \mathrm{eV})$. The photoelectrons were analyzed at a departure angle of $45^{\circ}$. Survey spectra were recorded in the range of $0-1400$ e V. During the experiment, the pressure was controlled below $6.7 \times 10^{-8} \mathrm{~Pa}$. All XPS spectra were fitted by using an XPS peak-fitting program called Thermo Avantage.

AFM imaging and force measurement.

The powder of the three metal salts was dissolved in PBS, respectively, and diluted to $10 \mu \mathrm{M}$ before use. For the comparison of $\mathrm{A} \beta 42$ aggregation events in the absence and presence of metal cations, the $\mathrm{A} \beta 42$ monolayers were incubated in blank solution (PBS) and metal ionic solutions $\left(\mathrm{Zn}^{2+}\right.$ solution, $\mathrm{Ca}^{2+}$ solution, and $\mathrm{Al}^{3+}$ solution) and 
placed in $37^{\circ} \mathrm{C}$ incubator for $24 \mathrm{~h}$ and $48 \mathrm{~h}$, respectively. Three-dimensional images of the incubated A 342 monolayers (with scanning size of $1 \mu \mathrm{m} \times 1 \mu \mathrm{m}$ ) were achieved at a resolution of $512 \times 512$ and a scanning rate of $1 \mathrm{~Hz}$. Surface topography of all samples were scanned by atomic force microscopy (JPK Nanowizard ${ }^{\circledR}$ II, Germany). Repeated cyclic scans were performed in CM-AFM. Three-dimensional topography of blank group and experimental groups recorded in different conditions was analyzed by imaging processing software which is provided by the manufacturer.

During force measurement, the functionalization of Au-coated probe tip with $A \beta 42$ film was prepared similarly as described above. The A 342 -modified tip scanned across the A $\beta 42$ monolayer. At a random site on the sample, the tip approached the surface of A 442 monolayer and then retracted. 10 force-distance curves were collected for each sample. In this study, Commercial Si3N4 cantilevers with spring constant of $0.07 \mathrm{~N} / \mathrm{m}$ (BudgetSensors, Innovative Solutions Bulgaria Ltd., Bulgaria) were used in contact mode of AFM (CM-AFM). The thickness of the gold layer on the tip is $70 \mathrm{~nm}$.

\section{SERS determination}

A $\beta 42$ monolayer was prepared by the method mentioned above. $10 \mu \mathrm{M}$ concentration of metal salts was dissolved in PBS solution. The prepared A 342 monolayer-modified substrate was placed in a clean liquid pool, $2 \mathrm{~mL}$ of blank solution (PBS), and metal ion solution $\left(\mathrm{Zn}^{2+}, \mathrm{Ca}^{2+}, \mathrm{Al}^{3+}\right)$ was added, respectively, and immersed in an incubator $\left(37^{\circ} \mathrm{C}\right)$ for $24 \mathrm{~h}$.

The Raman spectra of freshly prepared A $\beta 42$ monolayers were obtained from a confocal Raman spectrometer (LabRAM HR Evolution, HORIBA Jobin Yvon S.A.S. Co., France) with resolution of $1 \mathrm{~cm}^{-1}$. The laser was a He-Ne laser with excitation wavelength set at $633 \mathrm{~nm}$, laser power set at $6.0 \mathrm{mw}$, and the measurement range was $800 \sim 2800 \mathrm{~cm}^{-1}$. With PBS solution as blank control, the conformational changes of A $\beta 42$ with the addition of metal cations were determined by Raman spectroscopy. For each experimental group, the Raman experiment was repeated at least three times.

In addition, we used Levenberg-Marquardt algorithm for peak split and fitting of the Raman spectral bands (corresponding to the $\beta$-folded conformation) (about $1600 \sim 1700 \mathrm{~cm}^{-1}$ ) and the characteristic peaks corresponding to amide bond at about $1400 \mathrm{~cm}^{-1}$. During the SERS testing, the same sample parameters were set. The integration time of Raman data were initially set as $10 \mathrm{~s}$, and then the integration time was gradually increased to $60 \mathrm{~s}$.

\footnotetext{
Abbreviations

AFM: Atomic force microscope; SAM: Self-assembled monolayer; XPS: X-ray photoelectron spectroscopy; SERS: Surfaceenhanced Raman Scattering; AD: Alzheimer's disease; Aß: $\beta$-Amyloid peptides; MHA: 16-Mercaptohexadecanoic acid; EDC: 1-Ethyl-3-(dimethylaminopropyl)carbodiimide hydrochloride; NHS: N-Hydroxysulfosuccinimide; PBS: Phosphatebuffered saline.

Acknowledgements

Not applicable.

Authors' contributions

YX contributed to experimental design and manuscript writing. LY, YF, and HS performed data collection and analysis. JW was responsible for providing overall thinking. All the authors reviewed and approved the final version of the manuscript.
} 


\section{Funding}

This work was supported by National Major Scientific Research Instrument Development Project of NSFC (21827812) and Basic Research and Frontier Exploration Project of CSTC (cstc2018jcyjAX0758).

\section{Availability of data and materials}

The datasets used and analyzed during the current study are available from the corresponding author on reasonable request.

\section{Declarations}

Ethics approval and consent to participate

Not applicable.

\section{Consent for publication}

Not applicable.

\section{Competing interests}

The authors declare that they have no competing interests.

\section{Author details}

${ }^{1}$ Pharmaceutical Engineering Center, Chongqing Medical and Pharmaceutical College, Chongqing 401331, China. ${ }^{2}$ Key Laboratory of Biorheological Science and Technology, Ministry of Education, and Institute of Biochemistry and Biophysics, College of Bioengineering, Chongqing University, Chongqing 400044, China.

Received: 2 November 2021 Accepted: 21 December 2021

Published online: 30 December 2021

\section{References}

1. Shankar GM, Li S, Mehta TH, Garcia-Munoz A, Shepardson NE, Smith I, Brett FM, Farrell MA, Rowan MJ, Lemere CA, et al. Amyloid-beta protein dimers isolated directly from Alzheimer's brains impair synaptic plasticity and memory. Nat Med. 2008;14(8):837-42.

2. Smith C, Anderton BH. Dorothy-Russell-memorial-lecture-the molecular pathology of Alzheimers-disease-are we any closer to understanding the neurodegenerative process. Neuropathol Appl Neurobiol. 1994;20(4):322-38.

3. Tahirbegi IB, Pardo WA, Alvira M, Mir M, Samitier J. Amyloid A beta(42), a promoter of magnetite nanoparticle formation in Alzheimer's disease. Nanotechnology. 2016;27(46):465102.

4. Karran E, Mercken M, De Strooper B. The amyloid cascade hypothesis for Alzheimer's disease: an appraisal for the development of therapeutics. Nat Rev Drug Discovery. 2011;10(9):698-U1600.

5. Pauwels K, Williams TL, Morris KL, Jonckheere W, Vandersteen A, Kelly G, Schymkowitz J, Rousseau F, Pastore A, Serpell LC, Broersen K. Structural basis for increased toxicity of pathological A beta(42): A beta(40) ratios in Alzheimer disease. J Biol Chem. 2012;287(8):5650-60.

6. Williams TL, Johnson BRG, Urbanc B, Jenkins ATA, Connell SDA, Serpell LC. A beta 42 oligomers, but not fibrils, simultaneously bind to and cause damage to ganglioside-containing lipid membranes. Biochem J. 2011;439:67-77.

7. Smith DP, Smith DG, Curtain CC, Boas JF, Pilbrow JR, Ciccotosto GD, Lau T-L, Tew DJ, Perez K, Wade JD, et al, Copper-mediated amyloid-beta toxicity is associated with an intermolecular histidine bridge. J Biol Chem. 2006:281(22):15145-54.

8. Green KN, LaFerla FM. Linking calcium to A beta and Alzheimer's disease. Neuron. 2008;59(2):190-4.

9. Frederickson CJ, Koh JY, Bush Al. The neurobiology of zinc in health and disease. Nat Rev Neurosci. 2005;6(6):449-62.

10. Yumoto S, Kakimi S, Ohsaki A, Ishikawa A. Demonstration of aluminum in amyloid fibers in the cores of senile plaques in the brains of patients with Alzheimer's disease. J Inorg Biochem. 2009:103(11):1579-84.

11. Wang Y, Wang J, Huang S, Liu C, Fu Y. Evaluating the effect of aminoglycosides on the interaction between bovine serum albumins by atomic force microscopy. Int J Biol Macromol. 2019;134:28-35.

12. Wang C, Stanciu CE, Ehrhardt CJ, Yadavalli VK. Nanoscale characterization of forensically relevant epithelial cells and surface associated extracellular DNA. Forensic Sci Int. 2017;277:252-8.

13. Sapra KT, Besir S, Oesterhelt D, Muller DJ. Characterizing molecular interactions in different bacteriorhodopsin assemblies by single-molecule force spectroscopy. J Mol Biol. 2006;355(4):640-50.

14. Mullett WM, Lai EPC, Yeung JM. Surface plasmon resonance-based immunoassays. Methods. 2000;22(1):77-91.

15. Roda A, Pasini P, Mirasoli M, Michelini E, Guardigli M. Biotechnological applications of bioluminescence and chemiluminescence. Trends Biotechnol. 2004:22(6):295-303.

16. Lee DW. Revisiting the interaction force measurement between lipid bilayers using a surface forces apparatus (SFA). J Oleo Sci. 2018:67(11):1361-72.

17 Wang C, Hu R, Morrissey JJ, Kharasch ED, Singamaneni S. Single molecule force spectroscopy to compare natural versus artificial antibody-antigen interaction. Small. 2017;13(19):1604255.

18. Wang C, Ehrhardt CJ, Yadavalli VK. Nanoscale imaging and hydrophobicity mapping of the antimicrobial effect of copper on bacterial surfaces. Micron. 2016:88:16-23.

19. Kang L, Smith S, Wang C. Metal-organic framework preserves the biorecognition of antibodies on nanoscale surfaces validated by single-molecule force spectroscopy. ACS Appl Mater Interfaces. 2020;12(2):3011-20.

20. Han X, Sun S, He T. Preparation and photolithography of self-assembled monolayers of 10-mercaptodecanylphosphonic acid on glass mediated by zirconium for protein patterning. Colloids Surfaces B-Biointerfaces. 2013;108:66-71. 
21. Huang P, Song E, Sun Y, LiT, Wei D, Liu M, Wu Y. Schiff-based Pd(II)/Fe(III) bimetallic self-assembly monolayer-preparation, structure, catalytic dynamic and synergistic. Mol Catal. 2019;469:75-86.

22. Wang C, Yadavalli VK. Investigating biomolecular recognition at the cell surface using atomic force microscopy. Micron. 2014;60:5-17.

23. Quagliano LG. Observation of molecules adsorbed on III-V semiconductor quantum dots by surface-enhanced Raman scattering. J Am Chem Soc. 2004;126(23):7393-8.

24. Wang P, Liu Z. Darling-Dennison resonance of thiourea adsorbed on the silver electrode revealed by surface enhanced Raman spectroscopy. J Raman Spectrosc. 2013;44(9):1273-6.

25. Yin HJ, Chen ZY, Zhao YM, Lv MY, Shi CA, Wu ZL, Zhang X, Liu L, Wang ML, Xu HJ. Ag@Au core-shell dendrites: a stable, reusable and sensitive surface enhanced Raman scattering substrate. Sci Rep. 2015. https://doi.org/10.1038/ srep14502.

26 Lekka M, Kulik AJ, Jeney S, Raczkowska J, Lekki J, Budkowski A, Forro L. Friction force microscopy as an alternative method to probe molecular interactions. J Chem Phys. 2005;123(1):014702.

27. Ferretti S, Paynter S, Russell DA, Sapsford KE, Richardson DJ. Self-assembled monolayers: a versatile tool for the formulation of bio-surfaces. Trac-Trends Anal Chem. 2000;19(9):530-40.

28. Schwartz DK. Mechanisms and kinetics of self-assembled monolayer formation. Annu Rev Phys Chem. 2001;52:107-37.

29. Castner DG, Hinds K, Grainger DW. X-ray photoelectron spectroscopy sulfur $2 p$ study of organic thiol and disulfide binding interactions with gold surfaces. Langmuir. 1996;12(21):5083-6.

30. Martins MCL, Ratner BD, Barbosa MA. Protein adsorption on mixtures of hydroxyl- and methylterminated alkanethiols self-assembled monolavers. J Biomed Mater Res, Part A. 2003;67A(1):158-71.

31. Ishida T, Choi N, Mizutani W, Tokumoto H, Kojima I, Azehara H, Hokari H, Akiba U, Fujihira M. High-resolution X-ray photoelectron spectra of organosulfur monolayers on $\mathrm{Au}(111): \mathrm{S}(2 \mathrm{p})$ spectral dependence on molecular species. Langmuir. 1999;15(20):6799-806.

32. Ivanov YD, Frantsuzov PA, Bykov VA, Besedin SP, Hoa GHB, Archakov Al. Comparative investigation of PdR by usual and ultrafine atomic force microscopy. Anal Methods. 2010;2(6):688-93.

33. Brinet D, Gaie-Levrel F, Delatour V, Kaffy J, Ongeri S, Taverna M. In vitro monitoring of amyloid beta-peptide oligomerization by Electrospray differential mobility analysis: an alternative tool to evaluate Alzheimer's disease drug candidates. Talanta. 2017:165:84-91.

34. Alies B, Hureau C, Faller P. The role of metal ions in amyloid formation: general principles from model peptides. Metallomics. 2013;5(3):183-92

35. Banks WA, Niehoff ML, Drago D, Zatta P. Aluminum complexing enhances amyloid beta protein penetration of blood-brain barrier. Brain Res. 2006;1116:215-21.

36. Hoare DG, Koshland DE. A method for quantitative modification and estimation of carboxylic acid groups in proteins. J Biol Chem. 1967;242(10):2447-3000.

37. Wang C, Wang J, Deng L. Evaluating interaction forces between BSA and rabbit anti-BSA in sulphathiazole sodium, tylosin and levofloxacin solution by AFM. Nanoscale Res Lett. 2011;6:1-9.

38. Wakayama J, Sekiguchi H, Akanuma S, Ohtani T, Sugiyama S. Methods for reducing nonspecific interaction in antibody-antigen assay via atomic force microscopy. Anal Biochem. 2008;380(1):51-8.

\section{Publisher's Note}

Springer Nature remains neutral with regard to jurisdictional claims in published maps and institutional affiliations.

- fast, convenient online submission

- thorough peer review by experienced researchers in your field

- rapid publication on acceptance

- support for research data, including large and complex data types

- gold Open Access which fosters wider collaboration and increased citations

- maximum visibility for your research: over $100 \mathrm{M}$ website views per year

At BMC, research is always in progress.

Learn more biomedcentral.com/submissions 